\title{
The Coming Man from Canton: Chinese Experience in Montana, 1862-1943
}

\author{
Christopher W. Merritt, University of Nebraska Press and the Society for Historical \\ Archaeology, 2017. 304 pp., 29 illus., 22 tables, acknowledgments, refs., index. \\ $\$ 65.00$ cloth
}

\section{Roberta S. Greenwood}

Accepted: 20 November 2017 / Published online: 7 December 2017

(C) Society for Historical Archaeology 2017

Publications addressing the Chinese who came to California after the Gold Rush have largely focused on the artifacts they left behind, and not their daily lives or the factors that prompted their immigration. In fact, aside from Christopher W. Merritt's research in Montana and oral presentations by Sherri Gust and a few others at professional conferences, few authors have addressed Chinese settlements remote from the Pacific coast. This book, along with Anna Louise Fahy's presentation "Borderland Chinese: Their Arrival, Contributions, and Heritage in the El Paso Region" (El Paso Museum of Archaeology, August 19, 2017), greatly expands the literature by topic and by geography. Although Merritt devotes one chapter to archaeology, few of the sites discussed were excavated or even retained evidence of cultural resources, and the artifact discussions that are present here lack specific identifications or quantifications.

The book is essentially an historical context rather than a publication that is heavily informed by archaeological findings. The chapters are organized by time frames, each chapter introduced by local history and further characterized by a theme, such as expansion, restriction, diversification, or social organization. Demographics include a brief discussion of women and their roles, and exhaustive summaries of male occupations derived from United States federal census statistics. Laundering was the primary source of work, followed in order by cook,

R. S. Greenwood $(\bowtie)$

Greenwood and Associates, Pacific Palisades, CA 90272, U.S.A. e-mail: rsgreenwoo@aol.com gardener, laborer, mining, and merchant. Together, this constituted $75 \%$ of the Chinese labor market, which also included one barber, baker, doctor, prisoner, scavenger, and "capitalist." Job opportunities increased as the technology of mineral extraction evolved from placer mining to industrialized hard-rock operations.

On the archaeological sites, dietary remains revealed that the Chinese consumed a broad range of domestic animals and wild game, but no fish. The array included both American foods, condiments, and alcoholic beverages, as well as traditional homeland delicacies such as turtle. There was no evidence for plant foods, including any that the local Chinese would be growing, or other purchased perishables, recovered by archaeologists; it is unlikely organic remains survived in the soil. It is unclear whether factors affecting the Chinese diet were predominantly influenced by consumer choice or market availability.

This research is a worthy addition to the scant body of documented information about the daily life of the Chinese immigrants in America. Even fewer published resources bring the historical narrative into this relatively recent period. The book concludes with a valuable dissection of many of the prevailing myths about the Chinese experience, both in Montana and elsewhere. It is refreshing to see a publication that illuminates Chinese communities in the American interior, rather than coastal settlements. By using archaeology and primary historical research, along with a focus upon the details of daily life, and providing statistics to validate his conclusions, Merritt has offered a wellresearched contribution to the deeper understanding of the overseas Chinese. 